\title{
Surgical management of cellular congenital mesoblastic nephroma in a neonate: a case report and review of literature
}

\author{
Ali Ihab ${ }^{1 *}$, Al Otaibi Abdullah', Abduldaem Abdullah', Alonazi Mohammad ${ }^{1}$ and Nojoom Maha²
}

\begin{abstract}
Background: Congenital mesoblastic nephroma (CMN) is the most common type of renal stromal tumor in neonates. It is classified into cellular, classical, and mixed types. The multidisciplinary management approach is the mainstay of management. We are reporting a case of neonatal congenital mesoblastic nephroma in a full-term boy with intrauterine growth restriction and hypertension managed effectively in our institution.
\end{abstract}

Case presentation: A full-term boy with intrauterine growth restriction (IUGR) with a birth weight of $2.3 \mathrm{~kg}$, referred at birth with an abdominal mass. His antenatal scan at 35 weeks showed a cystic abdominal mass. On delivery, a huge visible abdominal mass of cystic consistency and smooth surface was noticed at the right side of the abdomen. blood pressure was $98 / 75 \mathrm{mmHg}$. It was responsive to hydralazine. Aldosterone and renin were significantly elevated at more than 100 and $500 \mathrm{ng} / \mathrm{dl}$, respectively. Serum neurone-specific enolase (NSE) was $35 \mathrm{ng} / \mathrm{ml}$ while alfa feto protein was (AFP) 50,000 klU/L. An abdominal ultrasound scan revealed an ill-defined large heterogeneous mass of $6.09 \times 6.5 \times 5.77 \mathrm{~cm}$ that arises from the right kidney. A computed tomography scan confirmed a right kidney mass with peripheral claw sign of the normal right renal tissue. It was crossing the midline and causing a mass effect on the adjacent structures. The right renal artery and vein were compressed and shifted posteriorly and inferomedially. Right radical nephrectomy was performed via a right lower transverse incision. The tumor was completely excised with a tumor weight of $270 \mathrm{~g}$ and a size of $10.5 \times 8 \times 5.5 \mathrm{~cm}$. Histopathological diagnosis was mesoblastic nephroma of a cellular type which was confirmed by immunohistochemistry. Post-operatively, the blood pressure has significantly reduced and antihypertensive medications were eventually weaned off. The multidisciplinary team decided to preserve chemotherapy only in case of recurrence. At 3 months follow-up, no features of recurrence were noticed based on surveillance ultrasonography.

Conclusion: Mesoblastic nephroma should be considered in any newborn with renal mass. The multidisciplinary team approach with aggressive management of hypertension, detailed radiological investigation, and complete tumor resection is fundamental for obtaining an excellent outcome for such entities.

Keywords: Cellular congenital mesoblastic Nephroma, Neonate, Surgery

\footnotetext{
* Correspondence: ihabtaha21@hotmail.com; iali@psmmc.med.sa

${ }^{1}$ Paediatric Surgery Department, Prince Sultan Military Medical City, Riyadh,

Saudi Arabia

Full list of author information is available at the end of the article
}

\section{Springer Open}

(c) The Author(s). 2021 Open Access This article is licensed under a Creative Commons Attribution 4.0 International License, which permits use, sharing, adaptation, distribution and reproduction in any medium or format, as long as you give appropriate credit to the original author(s) and the source, provide a link to the Creative Commons licence, and indicate if changes were made. The images or other third party material in this article are included in the article's Creative Commons licence, unless indicated otherwise in a credit line to the material. If material is not included in the article's Creative Commons licence and your intended use is not permitted by statutory regulation or exceeds the permitted use, you will need to obtain permission directly from the copyright holder. To view a copy of this licence, visit http://creativecommons.org/licenses/by/4.0/. 


\section{Background}

Congenital mesoblastic nephroma $(\mathrm{CMN})$ is the most common type of renal stromal tumor in a neonate with an incidence of $80 \%$ [1]. It was distinguished from Wilms tumor in 1967 by Bolande. Currently, it is classified into three histological patterns. This includes cellular, classical, and mixed CMN; each type accounts for 66,24 , and $10 \%$ of cases, respectively [2]. A multidisciplinary approach is the mainstay of management. Preoperative evaluation is essential to plan a successful procedure. Image-guided post-operative follow-up should be continued for a minimum period of 2 years [3]. We are reporting a case of neonatal congenital mesoblastic nephroma in a full-term boy with intrauterine growth restriction and hypertension which was managed effectively in our institution.

A review of literature was conducted in order to obtain the available data about this rare condition. PubMed and Google Scholar searched using mesoblastic nephroma, neonate, and pediatric surgery as keywords.

\section{Case presentation}

A full-term boy with intrauterine growth restriction (IUGR) was delivered via normal vertex delivery (NVD) with a birth weight of $2.3 \mathrm{~kg}$, referred at birth with an abdominal mass. His antenatal scan at 35 weeks showed a cystic abdominal mass. On delivery, the physical examination was unremarkable apart from the huge abdominal mass (Fig. 1). The mass was of cystic consistency and smooth surface mainly at the right side of the abdomen. Systolic blood pressure was initially $98 \mathrm{mmHg}$ and the diastolic was $75 \mathrm{mmHg}$. This elevated blood pressure was responsive to hydralazine therapy. Aldosterone and renin were significantly elevated at more than 100 and $500 \mathrm{ng} / \mathrm{dl}$, respectively. Serum neuron-specific enolase

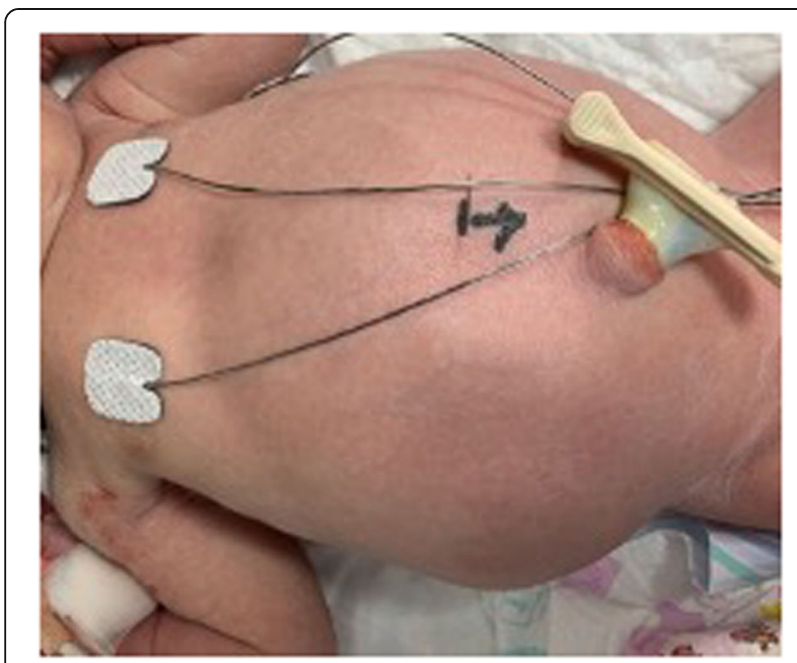

Fig. 1 Clinical exam with right side abdominal mass
(NSE) was $35 \mathrm{ng} / \mathrm{ml}$ while alfa feto protein was (AFP) $50,000 \mathrm{kIU} / \mathrm{L}$. Electrolyte, creatinine, and urinary vanillylmandelic acid levels were within normal limits. An abdominal ultrasound scan revealed an ill-defined large heterogeneous mass lesion measuring $6.09 \times 6.5 \times 5.77$ $\mathrm{cm}$, arising from the right kidney, which appears compressed and displaced posteriorly and inferiorly. The mass appears hypervascular and contains multiple cystic changes and heterogeneous echotexture. No gross calcifications were identified. The left kidney and both adrenal glands appear unremarkable. This was confirmed by a computer topographic scan and the mass was seen within the right kidney with peripheral claw sign of the normal right renal tissue measuring approximately $7.8 \times$ $6.8 \times 7.9 \mathrm{~cm}$ in transverse, anteroposterior, and longitudinal axis, respectively (Fig. 2). The lesion was crossing the midline and causing mass effect on the adjacent structures, and the IVC was compressed and shifted to the left side. The right renal artery and vein were compressed and shifted posteriorly and inferomedially. The left kidney was reported as normal in size, shape, and enhancement with no gross focal lesion and no distal lymph node involvement. Chest CT revealed no evidence of metastatic pulmonary disease.

Exploratory laparotomy was performed on the sixth day of life under general anesthesia on a supine position with back support. Right radical nephrectomy was performed via a right lower transverse incision. Right renal hilum was identified inferio-medial to the lesion and the stretched renal vessels were controlled. Tumor was completely excised with no spillage, and tumor bed was marked. There were no intra-operative complications, and the patient recovered smoothly from surgery. Postoperatively, the blood pressure reduced dramatically, and he was weaned of antihypertensive medication on the second post-operative day. Feeding was started on post-operative day 3. He was discharged home after reached full feeding.

The tumor (Fig. 3) weight $270 \mathrm{~g}$ and measured $10.5 \times$ $8 \times 5.5 \mathrm{~cm}$ were noted to be of the smooth outer surface and heterogenous yellow/tan cut surface with cystic and hemorrhagic foci. The capsule was intact and margins were free. Histopathological diagnosis was mesoblastic nephroma of cellular type confirmed by immunohistochemical stains which were negative for SMA (smooth muscle actin), Pan CK, synaptophysin, and desmin, focally positive for S100. All surgical resection margins are free of tumor which was focally present less than $1 \mathrm{~mm}$ from the inked margin. FISH translocation involved the ETV6 gene on chromosome 12.

Oncology tumor board labeled the case as stage 2 according to NCI guidelines. The multidisciplinary team including pediatric surgeon, neonatal intensive care physician, and pediatric oncologist decided to preserve 


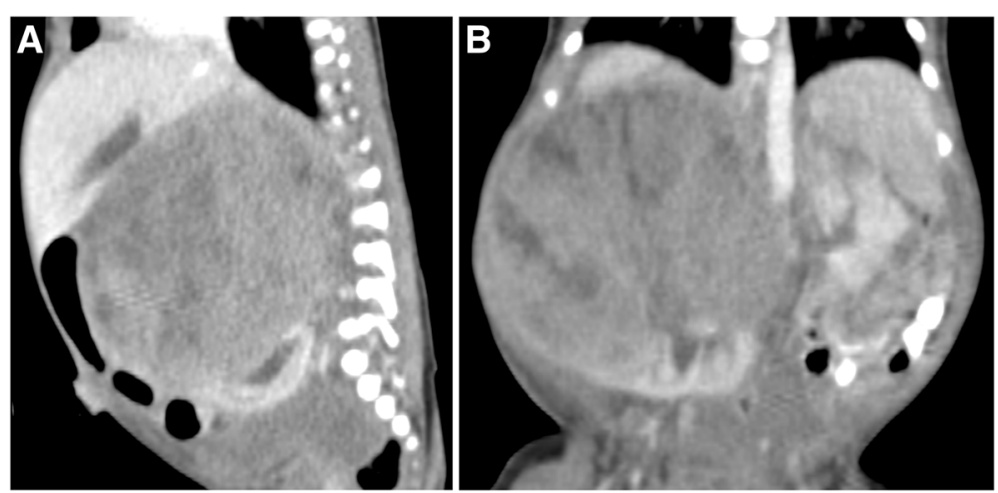

Fig. 2 A CT scan—sagittal view_showing the claw-like renal tissue and the hilum position which displaced medially and posteroinferiorly. B CT scan—coronal view—of the mass

chemotherapy only in case of recurrence. The child was seen in the clinic at the age of 3 months without any features of recurrence based on surveillance ultrasonography. Long-term follow-up as planned by our pediatric oncologist will continue 3 monthly for the first 2 years after surgery followed by 6 monthly in the subsequent 2 years and then yearly until at least 5 years of age.

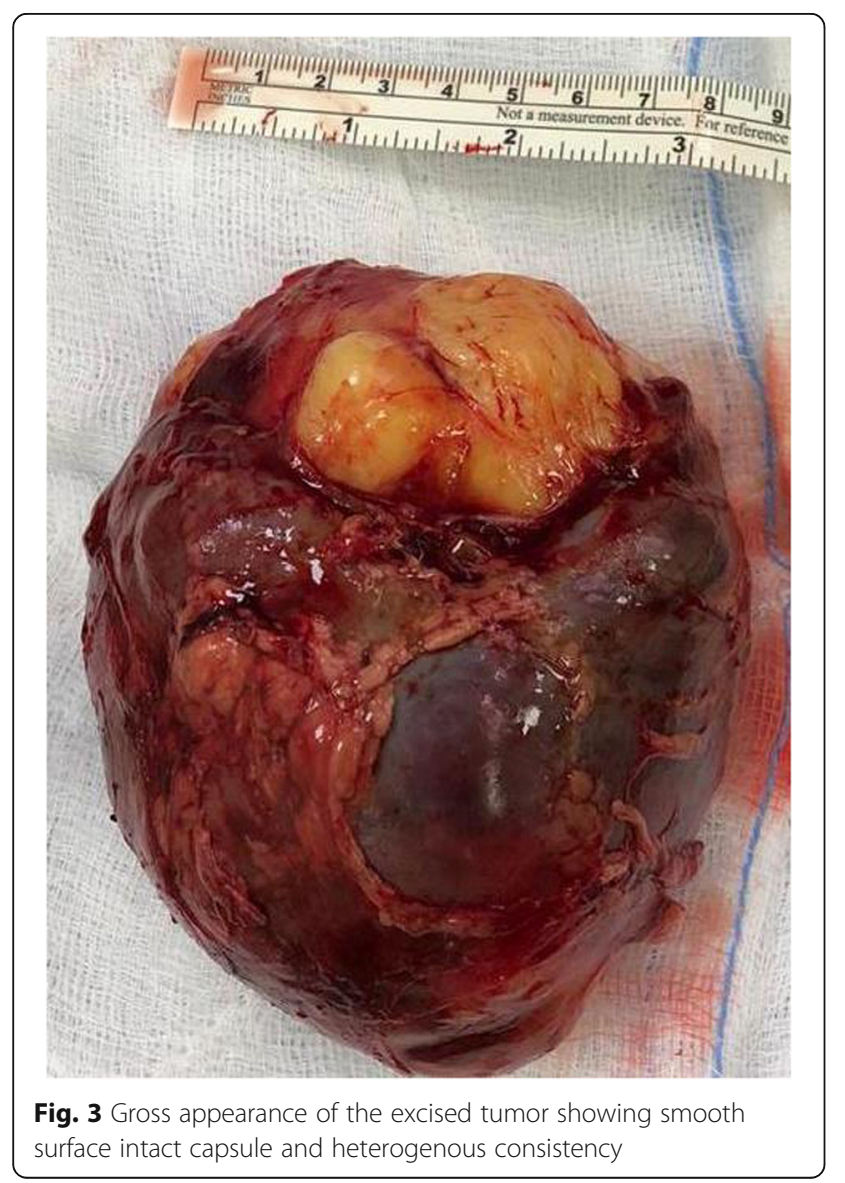

\section{Discussion}

We are reporting a neonate with mesoblastic nephroma which is a rare renal tumor in children that occurs with an incidence of $1: 125,000$ (4). It accounts for $3-10 \%$ of all pediatric renal tumors [4]. Most of those cases were presented at the neonatal period and $90 \%$ of cases were discovered before the age of 1 year [3]. Anunobi et al. reported its presence in 30 weeks preterm neonates [4]. It was found to have a slight female propensity with a rate of $1.5: 1$ [5].

The current classification includes three histopathological types. The main difference is related to the prognosis which influences the management protocol, as well as the long-term follow-up [5]. Another difference was noticed that the cellular type tends to have a later presentation, while the classical type tends to present early before the age of 6 months. It is worth mentioning that our case was a neonate of a cellular type in contrast to the previous consensus. The commonest type is the cellular which accounts for about two-thirds of the cases. Its main macroscopic histopathological features are consistent with large soft tumors with cystic components associated with areas of hemorrhage and necrosis. Microscopically, increase mitotic activity, small size stroma, and hyperchromatic nucleus with increased nuclear cytoplasmic ratio are the main features. On contrary, the classical type is less common with an incidence of $24 \%$. This type tends to present a benign feature. There are $10 \%$ of cases classified as mixed type which possess characteristics from both types [2].

Current advances in antenatal diagnosis enabled cases to be detected as early as 26 weeks gestational age [5]. Our case was discovered at 35 weeks; this was the only study done at the presentation. At birth, unliteral abdominal mass is the unique clinical feature of this tumor found in $73 \%$ of cases [6]. It is important to clarify the origin, size, and consistency of the tumor by conducting a careful clinical examination. Moreover, features of 


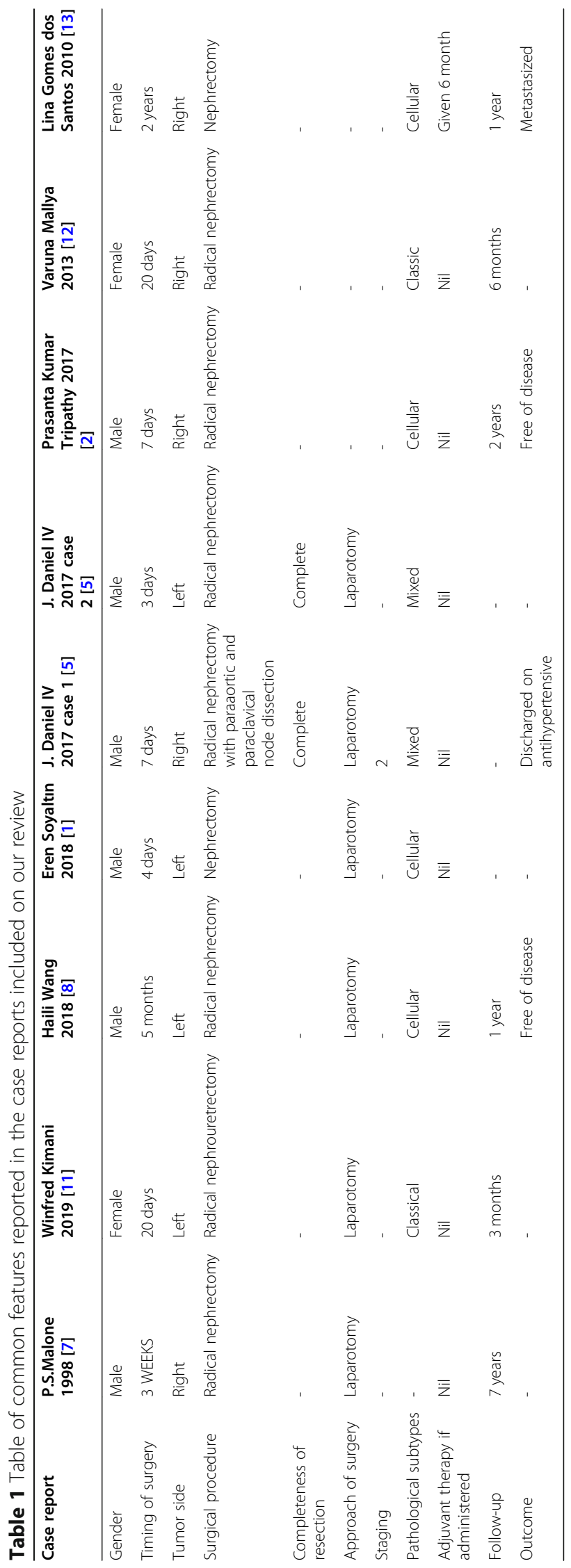


paraneoplastic syndrome were reported in several cases. Hypertension was prescribed in most of the cases with a reported percentage of 70\% [1]. The initial reading of blood pressure in our case was $98 / 75 \mathrm{mmHg}$; hence, the commencement of antihypertensive treatment was required. However, this was uncontrolled until the time of surgery. Post-operatively, a dramatic reduction in BP was noticed. This is explained by the presence of hyperrininemia as prescribed by Malone et al. [7]. Our patient's renin level was found to be $>500 \mathrm{ng} / \mathrm{dl}$, which is significantly higher than our laboratory's normal values of $2.21-35.3 \mathrm{ng} / \mathrm{dl}$. Hyperbilirubinemia and hematuria were reported as other neonatal clinical features [8]; neither was encountered in our case. Imaging studies are the cornerstone in pre-operative diagnosis. Ultrasonography can help to distinguish the origin and size, while computer topography gives specific information about local spread and distal metastasis. It is also important in long-term follow-up. Evaluation of the contralateral kidney is crucial to decide the course of management. In the study published by Chen et al. about specific computed tomography imaging characteristics of $\mathrm{CMN}$, they concluded that $\mathrm{CT}$ is accurate in characterizing the tumor and has advantages over ultrasonography. It provides better operator-independent repeatability and better comparability, offering the full tumor and peripheral structures characteristics [9]. We also recommend utilizing CT scan prior to surgery for better mapping of the anatomy which facilitates an oriented surgical approach.

Surgical resection is curative in most of the cases. Nevertheless, Zuo-Peng Wang et al. have suggested preoperative chemotherapy for patients who cannot receive surgery or older than 3 months of age [3]. Planning of the incision is critical in obtaining a good exposure in order to minimize excessive tumor handling and enable adequate resection. This can be judged by a detailed review of the clinical exam and image studies. Handling of tumor should be very cautious to avoid renin uncontrolled release and concomitant BP fluctuation that might lead to significant morbidity or mortality.

Postoperative multi-disciplinary follow-up based on the histopathological finding is recommended to determine the modality of management protocol and if further surgical intervention is needed. The reason for this as discussed by Susan Jehangir et al. that the recurrence and metastasis in CMN are significant and fatal. The percentage varies from $1 \%$ in classical type to $10 \%$ in cellular variant. The mortality is approaching half of the recurrence population. However, the treatment of options in these cases is mainly surgical. Unless, it is unoperable, where neoadjuvant chemotherapy is recommended [10]. Chemotherapy in our case is reserved for tumor recurrence or for evidence of metastasis should they occur during patient surveillance (Table 1).

\section{Conclusion}

Congenital mesoblastic nephroma should be considered in all newborns presented with renal mass. Aggressive management of hypertension to stabilize the patient for surgery should be carried out at the neonatal intensive care unit. A detailed radiological investigation is mandatory to plan successful surgical intervention. Excision of the tumor and post-operative multi-disciplinary team management are essential.

\section{Abbreviations \\ CMN: Congenital mesoblastic nephroma; IUGR: Intrauterine growth restriction; NVD: Normal vertex delivery; NSE: Serum neuron-specific enolase; AFP: Alfa feto protein; IVC: Inferior vena cava; SMA: Smooth muscle actin; $\mathrm{NCl}$ : National Cancer Institute}

\section{Acknowledgements}

To the Neonatal Intensive Care Unit, Prince Sultan Military Medical City. The Pediatric Oncology Department, Prince Sultan Military Medical City.

\section{Authors' contributions}

Al (1st and corresponding author) participated in pre-operative, operative, and post-operative management; collected, analyzed, and interpreted the patient data; and performed the literature review and the case write up. $\mathrm{AOA}$ is the consultant in charge of the management of the patient and performed the surgical resection of the mass. AA participated in the diagnosis, pre-operative, operative, and post-operative management. AM reviewed the case report, edited it and prepared it for publication, and obtained the ethical committee approval. NM performed the radiological review of the case. All authors read and approved the final manuscript.

\section{Funding}

No funding was obtained.

Availability of data and materials

Data and materials are available for review.

\section{Declarations}

Ethics approval and consent to participate

The Local Ethics Committee approved the report.

\section{Consent for publication}

This case report was requiring consent from the father for publishing the case features without disclosing their or the patient's identity. Written consent was obtained from the father as the patient is a neonate.

\section{Competing interests}

The author declares that they have competing interests.

\section{Author details}

${ }^{1}$ Paediatric Surgery Department, Prince Sultan Military Medical City, Riyadh, Saudi Arabia. ${ }^{2}$ Paediatric Radiology Department, Prince Sultan Military Medical City, Riyadh, Saudi Arabia.

Received: 30 December 2020 Accepted: 11 June 2021

Published online: 30 September 2021

References

1. Soyaltın E, Alaygut D, Alparslan C, Özdemir T, Arslansoyu-Çamlar S, Mutlubaş $F$, et al. A rare cause of neonatal hypertension: congenital mesoblastic nephroma, Case report. Turk J Pediatr. 2018;60(2):198-200. https://doi.org/1 0.24953/turkjped.2018.02.014

2. Tripathy PK, Behera S, Mohanty HK. Cellular congenital mesoblastic nephroma in a newborn, Clinical Image. J Neonat Surg. 2017;6(2):45

3. Wang Z-P, Li K, Dong K-R, Xiao X-M, Zhen S. Congenital mesoblastic nephroma: clinical analysis of eight cases and a review of the literature. Oncol Lett. 8:2007, 2014-11. 
4. Anunobi CC, Badmos KB, Onyekwelu VI, Ikeri NZ. Congenital mesoblastic nephroma in a premature neonate: a case report and review of literature. Niger J Clin Pract. 2014;17(2):255-9. https://doi.org/10.4103/1119-3077.12 7573.

5. Daniel J IV, Ruzic A, Dalland J, Miller V, Hanna M. Management of mixed type congenital mesoblastic nephroma: case series and review of the literature. J Neonatal-Perinatal Med. 2017;10(1):113-8. https://doi.org/1 $0.3233 / \mathrm{NPM}-1617$.

6. Lamb MG, Aldrink JH, O'Brien SH, Yin H, Arnold MA, Ranalli MA. Renal tumors in children younger than 12 months of age: a 65 -year single institution review. J Pediatr Hematol Oncol. 2017;39(2):103-7. https://doi. org/10.1097/MPH.0000000000000698.

7. Malone PS, Duffy PG, Ransley PG, Risdon RA, Cook T, Taylor M. Congenital mesoblastic nephroma, renin production, and hypertension. J Pediatr Surg. 1989:24(6):599-600.

8. Wang H, Yao Z, Liu Q. Congenital mesoblastic nephroma presenting with hematuria in a neonate. J Nippon Med Sch. 2018;85(5):297-9. https://doi. org/10.1272/jnms.JNMS.2018_85-48.

9. Chen Y, Zhou L, Liao N, Gao P, Chen L, Li X, et al. Specific computed tomography imaging characteristics of congenital mesoblastic nephroma and correlation with ultrasound and pathology. J Pediatr Urol. 2018;xx:1.e1-6.

10. Jehangir S, Kurian JJ, Selvarajah D, Thomas RJ, Holland AJA. Recurrent and metastatic congenital mesoblastic nephroma: where does the evidence stand? Pediatr Surg Int. 2020. https://doi.org/10.1007/s00383-017-4149-5.

11. Kimani W, Ashiundu E, Saula PW, Kimondo M, Keitany K. Congenital mesoblastic nephroma: Case study. J Pediatr Surg Case Rep. 2020;55:101336. https://doi.org/10.1016/j.epsc.2019.101336.

12. Maiiya V, Arora R, Gupta K, Sharm U. Congenital mesoblastic nephroma: a rare pediatric neoplasm. Turk J Pathol. 2013. https://doi.org/10.5146/tjpath.2 013.01149 .

13. dos Santos LG, de Sousa Ribeiro de Carvalho J, Reis MA, Sales RLB. Cellular congenital mesoblastic nephroma: case report. J Bras Nefrol. 2011;33(1):88-90.

\section{Publisher's Note}

Springer Nature remains neutral with regard to jurisdictional claims in published maps and institutional affiliations.

\section{Submit your manuscript to a SpringerOpen ${ }^{\circ}$ journal and benefit from:}

- Convenient online submission

- Rigorous peer review

- Open access: articles freely available online

High visibility within the field

- Retaining the copyright to your article

Submit your next manuscript at $\boldsymbol{\nabla}$ springeropen.com 